\title{
Research on the Function of Mainstream Media Comment Zone under the New Media Vision Field
}

\author{
Lijuan Chen
}

\author{
Xi'an Peihua University, Xian, Shaanxi, China, 710125
}

Keywords: Function, Mainstream Media, Comment Zone, New Media, Vision Field

\begin{abstract}
Due to the particularity of the nature and status of the mainstream media in our country, the importance of the mainstream media in guiding the public opinion is determined. The powerful and powerful public opinion guidance is the strong guarantee for the mainstream media in the face of the future development and requirements of the times. Therefore, on the basis of fully understanding various opportunities and challenges confronting the new era, as the mainstream media in our country, we must constantly enhance the initiative and tactic of public opinion guidance and constantly adapt and shape the public opinion ecology in line with social development so as to ensure social stability and economy development of services.
\end{abstract}

\section{Introduction}

With the development of communication technology, the channel of information dissemination has been greatly expanded. The emerging carrier of information dissemination continues to evolve, not only changing the traditional mode of transmission, but also indirectly affecting the audience's status and acceptance in the dissemination of information. Not only that, the boundaries between communicators and recipients are becoming increasingly blurred, and audiences can disseminate information and ideas through various channels. On the surface, although it promotes information prosperity and information democracy, it is also easy to form a fragmented, distorted, unfettered and easy to use public opinion ecological environment. This will objectively weaken the audience's trust in the mainstream media and at the same time increase the difficulty of mainstream media in guiding public opinion.

As an important public opinion position in our country, the mainstream media has the important function of integrating public opinion and guiding public opinion. The essence of media guidance is that the mainstream media should sort out and optimize important public opinion generated in the society and take the necessary measures to ensure that public opinion in the society can develop in the right direction. Social ideology, mainstream values and dominant cultural trends must be followed and must be conducive to safeguarding social stability and economic development. (1) At present, our country is in the transitional period of reform and opening up as well as the period of social conflicts. With the promotion of people's self-expression awareness and the diversification of channels of expression, the public opinion in the community has also shown a thriving scene. However, there appeared a major issue that aimed at how the mainstream media should guide social public opinion. Wrong public opinions may impact on the social structure, undermine social stability, dissolve the social forces and amplify the negative emotions in society, thus causing serious social crisis. All in all, the correct guidance and release of public opinion is the strong guarantee for the social stability, sustained economic development and cultural pluralism. Therefore, how to improve the ability of social public opinion to guide has become an important political task of the current mainstream media. This paper argues that based on the current situation analysis, the mainstream media in Chinese media guidance strategy needs to start from the following aspects.

\section{Public Opinion must Use New Media}

In general, public opinion can be divided into public opinion and public opinion. With the advent 
of the Internet age, due to the openness and convenience of its dissemination, online media often have more advantages in information dissemination than traditional media. In addition, in the process of disseminating information, the online media can easily obtain the first cause effect by virtue of its own advantages and publish information more timely than traditional media. Therefore, mainstream media build a new media communication platform so that both the subject and the object guided by the media can achieve real dialogue change the traditional one-way guidance of public opinion. Through this kind of dialogue, traditional mainstream media can capture news from the media of new media, understand the public's opinions about specific public affairs, set topics according to the actual conditions of public opinion, and guide the mainstream media of the society scientifically. In view of this, the mainstream media should clearly understand this situation and must learn how to make good use of new media in order to reverse the negative public opinion guidance.

The mainstream media should create first-rate news websites, for example, the People's Daily created by People's Daily, the Xinhuanet created by Xinhua News Agency, and so on. The era of new media has arrived and the mainstream media should have a sober judgment on this point. Only by virtue of its own advantages, we can create a first-rate news website, in order to have a foothold in the network media. Mainstream media websites not only produce news content, but also seek cooperation with news-licensed sites and sign feed agreements. In this way, not only can we expand the influence and competitiveness of the mainstream media websites, but also generate revenue for the mainstream media and achieve certain benefits. Today, the hottest new media is undoubtedly We-Chat. We-Chat has played a very important role in social events in recent years. The development of We-Chat has become the media carrier with the largest and largest increase of Internet users. We-Chat has become the object sought after by its unique mode of communication, and has also become the target of academic research and study. Many government and business units have opened the We-Chat platform and government affairs We-Chat has become a new thing gradually accepted by people. The launch of the government We-Chat will promptly release the latest guidelines and policies, the news is dynamic and become an important tool for the party and government agencies to understand public opinion and respond to public opinion. In addition, the mainstream media has also opened the We-Chat platform, releasing various kinds of information in time and actively interacting with Internet users. It has also become an important window for Internet users to understand the mainstream media. It is worth mentioning that the representative of mobile new media - mobile media, according to the data show that it has become the largest mobile Internet terminal has attracted the attention of the mainstream media, which also marks the mainstream media for mobile media in the media guidance a major reform direction. Fundamentally speaking, both traditional media and online media are social tools of information and tools of public opinion. In the end, people's opinions and public opinion can be expressed only after they are widely accepted by the public. In this sense, if an incident or event aroused the people's attention, then the traditional media and online media will actively intervene in the incident or event coverage, and ultimately the traditional media and online media in the event or event. Therefore, the effective agenda interaction between the emerging mainstream media and the traditional mainstream media can help to enhance the effectiveness of media guidance.

\section{The Mainstream Media Should Control the Intensity of Monitoring Public Opinions}

The mainstream media should monitor the dynamics of public opinion at any time, but also have a clear vision of the trend of public opinion. Public opinion collection, emphasis is fast and accurate, to accurately judge and promptly deals with. Public opinion monitoring also requires certain technical means. The general process is to analyze a certain public opinion event, determine the influence of public opinion based on the channel information such as news, forums and Weibo, and extract relevant information of public opinion from these information, and then organize analysis and research, formulate relevant handling systems in a timely manner, and conduct public opinion guidance through different channels and means. Because public opinion is highly directional, it 
must be decisive and timely in handling public opinion events, especially special social events. (5) The mainstream media is also an important institution for public opinion monitoring. Grasping the dynamics of public opinion cannot be strangled and blindly. It is necessary to adhere to the principle of online and offline linkage and give play to the leading role of the mainstream media. We must neither attack people's enthusiasm for participation nor do they should do well People's emotional guidance and ease, get people's support and recognition.

\section{Main Measures to Enhance the Mainstream Media Guidance}

With the development of society, obsolete means of reporting have been abandoned and new news reports must be created. First, new areas not covered in previous news often contain sufficient public opinion information, which requires journalists to develop. Secondly, in terms of the contents of the report, we must ensure that the masses gain experience from the stories reported and get enlightenment from them. At the same time, we must adhere to the principle of putting people first. We cannot over-speak, non-discrimination, non-flattery and put them equal to ourselves. When reporting on the news, we uphold fairness and justice, ensure the truth of the news, and express our emotions from the psychology of the general public. In the news appraisal, we must proceed from the reality in life and adopt the means that the masses are willing to understand and accept. When doing investigative news appraisals, insisting on the announcement of the findings and not making false statements, the appraisal can better reflect people's psychology and at the same time solve the problems that arise among the masses. Ensure the use of the language of the people, express the ideas of the masses of the people, express the appeals of the masses and solve the problems of the masses of the people. It is also an arduous and complicated task for the mainstream media to promote the media guidance under the new media vision. The mainstream media can guide the media to go forward. It not only relies on the support of the masses but also ensures that media companies only by persistently building outstanding media enterprises can we vigorously promote the vigorous development of the mainstream media and enhances the guidance of media in the mainstream media.

First, innovative ideas and enhance core competitiveness. Nowadays, with the development of major media, the competition of media quality has decided the sustainable development of media since the competition of pure program quality and competition of brand influence. Brand demonstrated the quality of the media as well as the image in the eyes of the people, more able to express the media's influence and competitiveness. Because the creation of the brand is not completed within a short period of time, we must create and maintain and enhance it through various measures such as constantly improving itself, vigorously publicizing, continuously reforming and improving, increasing social awareness and so on. Therefore, in order to enhance the leading force of public opinion, the mainstream media must enhance its own core competitiveness, vigorously innovate its concepts, not give up its old brands, vigorously create new brands, establish a new direction for the professional media industry, and vigorously promote brand engineering.

Second, innovative models and enhance media integration. The content of the news is limited, and the patterns are constantly changing. What kind of innovation model to make news can have greater effect is the mainstream media face new issues. First of all, in terms of content, traditional media have shown various problems in program production, such as many staff members, inefficiency, high costs, lack of quality and lack of creativity. Therefore, the mainstream media in the new media perspective should have new ideas, develop in new fields and accelerate the pace of updating. At the same time, they should also have some enlightenment and interest in people's lives. Secondly, in terms of the form of communication, the modern broadcasting media has gradually become digital, networked and converged. Nowadays it is a time when the Internet is prevalent. The Internet is gradually occupying people's lives. Broadcasting, as a media with many years of history, should be linked with the organic integration of new media and the new media complement each other to create a new pattern of communication so that we can quickly move forward with the new era of technology development, disseminate new technologies and acquire new opportunities 
brought by new media. To raise the leading force of public opinion in the mainstream media, we must ensure the correctness of public opinion. Only by guiding the correct direction of public opinion can we reach the goal of education and raising the people's concept. Only by using the mainstream media can we have influence, credibility and guidance. Therefore, the mainstream media should stipulate various rules and regulations so as to ensure that there is no error so as to ensure the correctness of public opinion guidance, so that the guidance of public opinion can be fully utilized. The innovation mechanism is actually an innovation check mechanism. According to the new knowledge and new requirements of the central, provincial and higher-level leaders on press publicity, the incentive mechanism for rewards and punishments should be set up to ensure that there will be no problems in the direction of public opinion and give full play to the guidance of public opinions.

\section{Conclusion}

Mainstream media in the face of the pressure of public opinion under the new situation, only follow the spread of the law, tap their own characteristics of communication, continuous innovation of media guidance, emphasis on efficiency and methods to make the mainstream media in leading the media to play a leading role to take the mainstream media should negative responsibility for social services.

\section{Acknowledgements}

Fund Project: Xi'an Peihua University campus-level topics 2017 school-level topics "UGC era mainstream media comment area function and communication strategy" research project of the stage results, project number PHKT17046

\section{References}

[1] Chen Dong, Yang Fang. "Microblogging heat" to improve the mainstream media public opinion of the cold thinking[J]. China Media Technology. 2012 (24)

[2] Burning. Traditional media to improve the ability of public opinion ontology research [J]. Hubei Social Sciences. 2011 (09)

[3] Wang Junchao. New media structure under the mainstream media guidance strategy [J]. News and writing. 2010 (12)

[4] Xie Yuejin. On the promotion of mainstream media public opinion guidance[J]. China Radio and Television Journal. 2008 (04)

[5] Zheng Baowei, Zou Jing. On the current strategy of public opinion in China[J]. Modern Communication (Journal of Communication University of China). 2007 (06) 